\title{
SCADoC
}

Infer, Interpret \& Inspire Science

International Journal of Dentistry and Oral Science (IJDOS)

ISSN: 2377-8075

\section{Attitudes Of Dentist Towards Communication Skills Learning}

Research Article

Sabika Saeed H.S. Al Muraikhi' ${ }^{1}$, Khalid Esmael M. E. Rahimi², Fatima Jassim M.H Albaker ${ }^{3}$, Ashwin C Shetty ${ }^{4 *}$

${ }^{1}$ Consultant, Department of Dental Diagnostic Surgical Science, Hamad Medical Corporation, Qatar.

2 Associate Consultant, Department of Dental Diagnostic Surgical Science, Hamad Medical Corporation, Qatar.

${ }^{3}$ Specialist, Department of Prosthodontics, Hamad Medical Corporation, Qatar.

${ }^{4}$ Assistant Professor, Vice Deanship for Postgraduate Studies and Scientific Research, Imam Abdulrahman Bin Faisal University, Kingdom of Saudi Arabia.

\section{Abstract}

Background: Communication is a key component of the patient and dentist relationship.

Objectives: This study was done to determine the attitude of dentist toward learning communication skills and to recognizethe factors influencing attitude toward learning communication skills.

Materials and Method: A cross-sectional study using a self-administered, 26-item, adapted Communication Skills Attitude Scale (CSAS) was carried out among dentist working in a public sector hospital in Qatar. From the adapted CSAS, positive attitude score (PAS) and negative attitude score (NAS) were determined. Obtained data was statistically analyzed using SPSS version 20 with non-parametric tests.

Result: Fifty-nine dentists completed the survey giving an overall response rate of 53.6\%. The average (SD) PAS and NAS scores were $3.98(\mathrm{SD}=0.54)$ and $3.26(\mathrm{SD}=0.49)$ respectively. Female dentist was more positive towards learning communication skills than male.There was no substantial association was established between both PAS and NAS scores and respondents' age.

Conclusion: Dentists' had both positive and negative attitudes towards learning communication skills.It is suggested to presentcommunication skills formal training gatherings based on higher NAS scores.

Keywords: Attitudes; Communication Skills; Dentist; Learning; Patient.

\section{Introduction}

Communication is akey component of the patient and dentist relationship. Communication between patients and healthcare professionals is a fundamental process within the patient-clinician relationship from the initial consultation onwards. Hence, it is an area recognized to beof consideration during undergraduate training for dentists [1]. Studies have reported that dental students have positive attitudes towards learning communication skills [2, 3]. It is essential that dental schools certify that undergraduates are effectively trained in communication skills [4].

It is important that dental students are offered with skills-based communication training to be better prepared for clinical practice. This will facilitate them to encounter with patient anxiety, recognize ethical issues, and identify important psychosocial factors leading to more precise diagnosis and treatment, thus improving patient satisfaction and safety. It is imperative to be able to com- municate well with patients, to efficiently collect and convey information, use effective listening skills, manage patient emotions delicately, and express empathy, rapport, ethical consciousness, and professionalism [5].

It has been observed that students with good communication skills were associated with positive attitudes towards communication skills learning and those with poor communication skills were associated with negative attitudes towards communication skills learning $[6,7]$. Moreover, some demographic characteristics have been determined as important in health care communication. One such characteristics is gender which happens to impact both attitude towards interpersonal skills and self-assessment of ability, while females are more likely to exhibit positive attitudes towards communication skills training than males [8].

A study on dental interns reported that females and those with training in communication skills were associated with positive

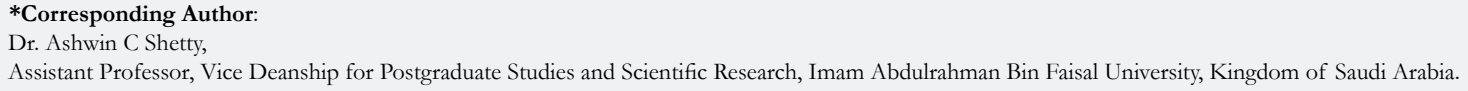

Citation: Sabika Saeed H.S. Al Muraikhi, Khalid Esmael M. E. Rahimi, Fatima Jassim M.H Albaker, Ashwin C Shetty. Attitudes Of Dentist Towards Communication Skills Learning. Int J Dentistry Oral Sci. 2020;7(12):1187-1192. doi: http://dx.doi.org/10.19070/2377-8075-20000235

Copyright: Ashwin C Shetty ${ }^{\circ} 2020$. This is an open-access article distributed under the terms of the Creative Commons Attribution License, which permits unrestricted use, distribution and reproduction in any medium, provided the original author and source are credited. 
attitudes towards learning communication skills [9]. Another study concluded that dentists, patients, and students contemplate professional communication skills are important in the dentistpatient relationship [10]. However, there is no evidence on the attitudes toward communication skills learning among dentist in Qatar. Hence, the aim of this study is to assess the attitude of dentist toward learning communication skills, to recognize the factors influencing attitude toward learning communication skills, and to suggest the inclusion of appropriate communication skill course.

\section{Materials and Methods}

Using a self-administered question, a cross-sectional study was done on 26-item of adapted Communication Skills Attitude Scale (CSAS) was performed amongst dentist employed in a publicly owned hospital in Qatar. The CSAS was originally developed for assessing medical students' attitudes towards communication skills learning. For dental use CSAS was modified and referred to as the Dental Communication Skills Attitude Scale (DCSAS). Key words were altered to "dental" or "dentistry" from "medicine" or "medical," and the word "doctor" was replaced by "dentist" where appropriate.Ethics approval for the study was obtained from the medical research center (\#16071).Informed consent was obtained from the participants. Anonymity and confidentiality were assured.

The questionnaire was divided into two partsand administered in English language to all dentists. Part A consisted of demographic questions. Part B consisted of the 26-item validated DCSAS questionnaire with two sub-scales: Positive Attitude Subscale (PAS) and Negative Attitude Subscale (NAS). The PAS consisted of 13 items (items one, four, five, seven, nine, ten, twelve, fourteen, sixteen, eighteen, twenty-one, twenty-three, and twenty-five) representing positive attitudes towards communications skills learning. The NAS consisted of 13 items (items two, three, six, eight, eleven, thirteen, fifteen, seventeen, nineteen, twenty, twenty-two, twenty-four, and twenty-six) representing negative attitudes towards communication skills learning.

The 26-item questionnaire was on a five-point Likert scale ranging from 1 (strongly agree) to 5 (strongly disagree). Overall, two scores wereconcluded from the adapted CSAS: the average PAS and NAS scores. They were determined by summing the scores of the 13 PAS and 13NAS items, respectively, and dividing them by the number of items in each scale. The scores range from 13 to 65 for both PAS and NAS. The highest average score suggests stronger attitude.
Data was analyzed using IBM SPSS version 22.0. Univariate analysis was performed to present the overview of the findings. Non-parametric tests such as Spearman's r, Mann-Whitney, and Kruskal-Walliswere used to determine the relationships between dependent (PAS and NAS scores) and independent (demographic) variables. A $\mathrm{p}$ value of $\leq 0.05$ was considered as statistically significant.

\section{Results}

Fifty-nine dentists completed the survey out of a total of 92 dentists, giving an overall response rate of $64.1 \%$. Table 1 shows the frequency distribution of demographic variables of the sample. The median age of the dentists was 36-45 years. Most of the dentist were female $(79.3 \%, n=46)$. There was no statistically significant association between age and gender $(\mathrm{p}>0.05)$.

Table 2 shows the overall mean value of the responses for each item. The mean value of the responses for each item was examined stratifying by demographic subgroups. A higher score indicates a more positive attitude towards learning communication skills. Analysis of the data on the dentists' attitudes towards communication skills learning showed that both male and female dentists possessed positive and negative attitudes towards communication skills learning.

As for the individual items, there were statistically significant differences between males and females in the mean value of the responses for only two of the twenty-six retained survey items $(p<0.05)$ (Table 3). Female dentists were more positive towards learning communication skills than male. Females scored higher on the PAS and males scored higher on the NAS.There were no statistically significant differences when stratified according to age group (Table 4).

The mean (SD) PAS and NAS scores were $3.98(\mathrm{SD}=0.54)$ and $3.26(\mathrm{SD}=0.49)$ respectively. Bivariate analysis was conducted to ascertain the relationships between the scores on the PAS and NAS of the dentist and their demographic characteristics. The mean PAS score was higher among females (mean $=4.03$, $\mathrm{SD}=0.51$ ) compared to males (mean $=3.78, \mathrm{SD}=0.66$ ). However, it was statistically not significant $(\mathrm{p}>0.05)$. The mean NAS score for the males (mean $=3.34, \mathrm{SD}=0.13$ ) was higher than females (mean $=3.24, \mathrm{SD}=0.55$ ) but was statistically not significant $(\mathrm{p}>0.05)$.

No significant correlation was found between the mean PAS score and respondents' age (rho $=-0.198, \mathrm{p}>0.05)$. This suggests that as age increased, mean PAS score decreased. The mean NAS score

Table 1. Demographics characteristics of the sample.

\begin{tabular}{|c|c|c|c|}
\hline \multicolumn{2}{|c|}{ Characteristics } & Frequency (n) & Percent (\%) \\
\hline \multirow{4}{*}{$\begin{array}{c}\text { Age (in } \\
\text { years) }\end{array}$} & $25-34$ & 17 & 29.3 \\
\cline { 2 - 4 } & $35-44$ & 29 & 50 \\
\cline { 2 - 4 } & $45-54$ & 8 & 13.8 \\
\cline { 2 - 4 } & $55-64$ & 4 & 6.9 \\
\hline \multirow{2}{*}{ Gender } & Male & 12 & 20.7 \\
\cline { 2 - 4 } & Female & 46 & 79.3 \\
\hline
\end{tabular}


Table 2. Overall scale item mean values.

\begin{tabular}{|c|c|c|}
\hline \multicolumn{2}{|c|}{ Items } & Mean \\
\hline \multicolumn{2}{|c|}{ 1. In order to be a good dentist, I must have good communication skills. } & 4.61 \\
\hline \multicolumn{2}{|c|}{ 2. I can't see the point in learning communication skills. $\dagger$} & 3.93 \\
\hline \multicolumn{2}{|r|}{ 3. Nobody is going to fail his or her dental degree for having poor communication skills. $\dagger$} & 3.09 \\
\hline \multicolumn{2}{|r|}{ 4. Developing my communication skills is just as important as developing my knowledge of dentistry. } & 4.16 \\
\hline \multicolumn{2}{|r|}{ 5. Learning communication skills has helped me or will help me respect patients. } & 4.25 \\
\hline \multicolumn{2}{|c|}{ 6. I haven't got time to learn communication skills. $\dagger$} & 3.36 \\
\hline \multicolumn{2}{|c|}{ 7. Learning communication skills is interesting. } & 3.97 \\
\hline \multicolumn{2}{|c|}{ 8. I can't be bothered to turn up to sessions on communication skills. $\dagger$} & 2.24 \\
\hline \multicolumn{2}{|c|}{ 9. Learning communication skills has helped or will facilitate my team-working skills. } & 4.27 \\
\hline \multicolumn{2}{|c|}{ 10. Learning communication skills has improved my ability to communicate with patients. } & 4.22 \\
\hline \multicolumn{2}{|c|}{ 11. Communication skills teaches the obvious and then complicates it. $\dagger$} & 2.75 \\
\hline \multicolumn{2}{|c|}{ 12. Learning communication skills is fun. } & 3.2 \\
\hline \multicolumn{2}{|c|}{ 13. Learning communication skills is too easy. $\dagger$} & 2.98 \\
\hline \multicolumn{2}{|c|}{ 14. Learning communication skills has helped or will help me respect my colleagues. } & 3.90 \\
\hline \multicolumn{2}{|r|}{ 15. I find it difficult to trust information about communication skills given to me by non-clinical lecturers. $\dagger$} & 3.23 \\
\hline \multicolumn{2}{|r|}{$\begin{array}{l}\text { 16. Learning communication skills has helped or will help me recognize patients' rights regarding confiden- } \\
\text { tiality and informed consent. }\end{array}$} & 3.90 \\
\hline \multicolumn{2}{|r|}{ 17. Communication skills teaching would have a better image if it sounded more like a science subject. $\dagger$} & 2.80 \\
\hline \multicolumn{2}{|r|}{ 18. When applying for dentistry, I thought it was a really good idea to learn communication skills. } & 3.48 \\
\hline \multicolumn{2}{|r|}{ 19. I don't need good communication skills to be a dentist. $†$} & 4.12 \\
\hline \multicolumn{2}{|c|}{ 20. I find it hard to admit to having some problems with my communication skills. $\dagger$} & 3.31 \\
\hline \multicolumn{2}{|r|}{ 21. I think it's really useful learning communication skills for the dental degree. } & 3.97 \\
\hline \multicolumn{2}{|r|}{ 22. My ability to pass exams will get me through dental school rather than my ability to communicate. $\dagger$} & 3.15 \\
\hline \multicolumn{2}{|c|}{ 23. Learning communication skills is applicable to learning dentistry. } & 3.59 \\
\hline \multicolumn{2}{|r|}{ 24. I find it difficult to take communication skills learning seriously. $\dagger$} & 3.54 \\
\hline \multicolumn{2}{|r|}{ 25. Learning communication skills is important because my ability to communicate is a lifelong skill. } & 4.24 \\
\hline \multicolumn{2}{|r|}{ 26. Communication skills learning should be left to psychology students, not dental students. $†$} & 3.96 \\
\hline \multirow{2}{*}{ Means } & \begin{tabular}{|c|} 
\\
\end{tabular} & 3.98 \\
\hline & NAS & 3.26 \\
\hline
\end{tabular}

†Item was negatively phrased.

Table 3. Scale item mean values stratified by gender.

\begin{tabular}{|l|c|c|c|}
\hline \multicolumn{1}{|c|}{ Items } & \multicolumn{2}{c|}{ Gender } & \multirow{2}{*}{ p value } \\
\cline { 2 - 4 } & Male & Female & \\
\hline 1. In order to be a good dentist, I must have good communication skills. & 4.83 & 4.57 & 0.239 \\
\hline 2. I can't see the point in learning communication skills. $\dagger$ & 4.33 & 3.84 & 0.224 \\
\hline 3. Nobody is going to fail his or her dental degree for having poor communication skills. $\dagger$ & 2.75 & 3.20 & 0.181 \\
\hline $\begin{array}{l}\text { 4. Developing my communication skills is just as important as developing my knowledge } \\
\text { of dentistry. }\end{array}$ & 4.00 & 4.20 & 0.297 \\
\hline 5. Learning communication skills has helped me or will help me respect patients. & 4.25 & 4.28 & 0.628 \\
\hline 6. I haven't got time to learn communication skills. $\dagger$ & 3.33 & 3.39 & 0.874 \\
\hline 7. Learning communication skills is interesting. & 4.00 & 3.96 & 0.824 \\
\hline 8. I can't be bothered to turn up to sessions on communication skills. $\dagger$ & 2.33 & 2.22 & 0.443 \\
\hline 9. Learning communication skills has helped or will facilitate my team-working skills. & 3.92 & 4.35 & 0.154 \\
\hline 10. Learning communication skills has improved my ability to communicate with patients. & 3.83 & 4.31 & 0.074 \\
\hline 11. Communication skills teaches the obvious and then complicates it.† & 2.91 & 2.70 & 0.496 \\
\hline 12. Learning communication skills is fun. & 3.00 & 3.26 & 0.383 \\
\hline 13. Learning communication skills is too easy. $†$ & 3.42 & 2.87 & $0.049 *$ \\
\hline
\end{tabular}




\begin{tabular}{|l|c|c|c|}
\hline 14. Learning communication skills has helped or will help me respect my colleagues. & 3.25 & 4.04 & $0.028^{*}$ \\
\hline $\begin{array}{l}\text { 15. I find it difficult to trust information about communication skills given to me by non- } \\
\text { clinical lecturers. }\end{array}$ & 3.18 & 3.23 & 0.991 \\
\hline $\begin{array}{l}\text { 16. Learning communication skills has helped or will help me recognize patients' rights } \\
\text { regarding confidentiality and informed consent. }\end{array}$ & 3.50 & 3.98 & 0.164 \\
\hline $\begin{array}{l}\text { 17. Communication skills teaching would have a better image if it sounded more like a } \\
\text { science subject. }\end{array}$ & 2.75 & 2.83 & 0.984 \\
\hline $\begin{array}{l}\text { 18. When applying for dentistry, I thought it was a really good idea to learn communica- } \\
\text { tion skills. }\end{array}$ & 3.33 & 3.51 & 0.599 \\
\hline $\begin{array}{l}\text { 19. I don't need good communication skills to be a dentist. } \dagger \\
\text { 20. I find it hard to admit to having some problems with my communication skills. } \dagger\end{array}$ & 4.45 & 4.04 & 0.313 \\
\hline 21. I think it's really useful learning communication skills for the dental degree. & 3.83 & 3.98 & 0.431 \\
\hline $\begin{array}{l}\text { 22. My ability to pass exams will get me through dental school rather than my ability to } \\
\text { communicate. }\end{array}$ & 3.42 & 3.09 & 0.388 \\
\hline 23. Learning communication skills is applicable to learning dentistry. & 3.08 & 3.72 & 0.089 \\
\hline 24. I find it difficult to take communication skills learning seriously. $\dagger$ & 3.58 & 3.50 & 0.801 \\
\hline $\begin{array}{l}\text { 25. Learning communication skills is important because my ability to communicate is a } \\
\text { lifelong skill. }\end{array}$ & 4.25 & 4.22 & 0.950 \\
\hline $\begin{array}{l}\text { 26. Communication skills learning should be left to psychology students, not dental stu- } \\
\text { dents. }\end{array}$ & 3.82 & 3.98 & 0.480 \\
\hline \begin{tabular}{l} 
Means NAS \\
\hline
\end{tabular} & 3.78 & 4.03 & 0.222 \\
\hline
\end{tabular}

†Item was negatively phrased. * Statistically significant

Table 4. Scale item mean values stratified by age (in years).

\begin{tabular}{|c|c|c|c|c|c|}
\hline \multirow{2}{*}{ Items } & \multicolumn{4}{|c|}{ Age } & \multirow{2}{*}{$\mathrm{p}$ value } \\
\hline & $25-34$ & $35-44$ & $45-54$ & $55-64$ & \\
\hline 1. In order to be a good dentist, I must have good communication skills. & 4.59 & 4.59 & 4.63 & 5.00 & 0.627 \\
\hline 2. I can't see the point in learning communication skills. $\dagger$ & 3.81 & 4.00 & 2.25 & 1.50 & 0.587 \\
\hline $\begin{array}{l}\text { 3. Nobody is going to fail his or her dental degree for having poor communica- } \\
\text { tion skills. } \dagger\end{array}$ & 3.19 & 3.07 & 3.00 & 3.25 & 0.936 \\
\hline $\begin{array}{l}\text { 4. Developing my communication skills is just as important as developing my } \\
\text { knowledge of dentistry. }\end{array}$ & 4.25 & 4.14 & 4.25 & 3.75 & 0.519 \\
\hline 5. Learning communication skills has helped me or will help me respect patients. & 4.50 & 4.14 & 4.37 & 3.75 & 0.144 \\
\hline 6. I haven't got time to learn communication skills. $\dagger$ & 3.47 & 3.24 & 3.62 & 3.50 & 0.820 \\
\hline 7. Learning communication skills is interesting. & 4.35 & 3.79 & 4.00 & 3.50 & 0.165 \\
\hline 8. I can't be bothered to turn up to sessions on communication skills. $\dagger$ & 2.47 & 2.11 & 2.13 & 2.50 & 0.790 \\
\hline $\begin{array}{l}\text { 9. Learning communication skills has helped or will facilitate my team-working } \\
\text { skills. }\end{array}$ & 4.53 & 4.17 & 4.25 & 3.75 & 0.491 \\
\hline $\begin{array}{l}\text { 10. Learning communication skills has improved my ability to communicate } \\
\text { with patients. }\end{array}$ & 4.53 & 3.93 & 4.63 & 4.00 & 0.138 \\
\hline 11. Communication skills teaches the obvious and then complicates it. $\dagger$ & 3.06 & 2.59 & 2.75 & 2.33 & 0.732 \\
\hline 12. Learning communication skills is fun. & 3.41 & 3.21 & 3.13 & 2.50 & 0.325 \\
\hline 13. Learning communication skills is too easy. $\dagger$ & 2.76 & 3.07 & 3.00 & 3.25 & 0.629 \\
\hline $\begin{array}{l}\text { 14. Learning communication skills has helped or will help me respect my col- } \\
\text { leagues. }\end{array}$ & 4.24 & 3.72 & 3.88 & 3.50 & 0.316 \\
\hline $\begin{array}{l}\text { 15. I find it difficult to trust information about communication skills given to } \\
\text { me by non-clinical lecturers. } \dagger\end{array}$ & 3.33 & 3.25 & 3.38 & 2.25 & 0.505 \\
\hline $\begin{array}{l}\text { 16. Learning communication skills has helped or will help me recognize pa- } \\
\text { tients' rights regarding confidentiality and informed consent. }\end{array}$ & 4.18 & 3.76 & 3.88 & 3.50 & 0.418 \\
\hline $\begin{array}{l}\text { 17. Communication skills teaching would have a better image if it sounded more } \\
\text { like a science subject. } \dagger\end{array}$ & 2.53 & 2.76 & 3.38 & 3.25 & 0.282 \\
\hline
\end{tabular}




\begin{tabular}{|c|c|c|c|c|c|c|}
\hline \multicolumn{2}{|c|}{$\begin{array}{l}\text { 18. When applying for dentistry, I thought it was a really good idea to learn } \\
\text { communication skills. }\end{array}$} & 3.76 & 3.36 & 3.63 & 2.75 & 0.308 \\
\hline \multicolumn{2}{|c|}{ 19. I don't need good communication skills to be a dentist. $\dagger$} & 3.88 & 4.21 & 4.14 & 4.50 & 0.889 \\
\hline \multicolumn{2}{|c|}{$\begin{array}{l}\text { 20. I find it hard to admit to having some problems with my communication } \\
\text { skills. } \dagger\end{array}$} & 3.18 & 3.34 & 3.50 & 3.00 & 0.795 \\
\hline \multicolumn{2}{|c|}{ 21. I think it's really useful learning communication skills for the dental degree. } & 3.88 & 4.00 & 4.00 & 3.75 & 0.913 \\
\hline \multicolumn{2}{|c|}{$\begin{array}{l}\text { 22. My ability to pass exams will get me through dental school rather than my } \\
\text { ability to communicate. } \dagger\end{array}$} & 2.94 & 3.21 & 3.38 & 3.25 & 0.778 \\
\hline \multicolumn{2}{|c|}{ 23. Learning communication skills is applicable to learning dentistry. } & 3.82 & 3.52 & 3.25 & 3.75 & 0.705 \\
\hline \multicolumn{2}{|c|}{ 24. I find it difficult to take communication skills learning seriously. $\dagger$} & 3.47 & 3.48 & 3.63 & 3.75 & 0.926 \\
\hline \multicolumn{2}{|c|}{$\begin{array}{l}\text { 25. Learning communication skills is important because my ability to commu- } \\
\text { nicate is a lifelong skill. }\end{array}$} & 4.47 & 4.10 & 4.13 & 4.25 & 0.646 \\
\hline \multicolumn{2}{|c|}{$\begin{array}{l}\text { 26. Communication skills learning should be left to psychology students, not } \\
\text { dental students. } \dagger\end{array}$} & 3.75 & 4.00 & 4.50 & 3.25 & 0.131 \\
\hline \multirow{2}{*}{ Means } & PAS & 4.20 & 3.88 & 4.00 & 3.67 & 0.260 \\
\hline & NAS & 3.20 & 3.26 & 3.39 & 3.29 & 0.898 \\
\hline
\end{tabular}

†Item was negatively phrased.

did not correlate significantly with respondents' age. However, the trend was not statistically significant ( $r h o=0.035, \mathrm{p}>0.05)$. This suggests that as age increased, mean NAS score increased.

\section{Discussion}

A good dentist-patient relationship comprises wide-ranging set of skills, contemplating psychological, pharmacological, and interpersonal and communication skills [11]. Communication with patients is not constrained to only exchange of information, instead involve creating, nurturing, and maintaining the doctor-patient relationship [12]. An effective communication benefits both patients and dentists [13]. On the contrary, poor communication is the most common source of patient dissatisfaction [14]. This is the first study identifying factors influencing attitude toward learning communication skills among dentist in Qatar.

This study used an adapted CSAS for measuring dentist attitudes towards communication skills learning. The finding of the study showed that dentist had both positive and negative attitudes towards communication skills learning. The mean PAS score in the current study was in comparison to that reported in a previous study, whereas the mean NAS score was higher [6]. The mean PAS score of female dentists was higher than the males. The better attitudes towards communication skills learning of female gender are consistent with previous studies that found a similar trend $[15,16]$.

Past research has shown that communication skills can be improved through participation in basic communication skills courses $[3,15]$. There is huge support for the fact that communication can be taught and learned [17]. There is an importance on the necessity for teaching communication skills in dentistry and for educational research assessing the efficiency of communication skills-based teaching programs [5]. Hence, dental educators oughtto pay more attention to the significance of communication skills for the dentists.

There was a lack of statistically statistical relation between the demographics and the PAS and NAS scores. However, the present study had certain limitations. The scale was administered in Eng- lish and dentist may have interpreted the scale in a different manner. The response rate of the dentist may have biased the scores. The sample size may possibly have led to type II error. Some of the analysis, particularly factor analysis that yield multiple factors (Learning, Importance, Quality, and Success) may produce different results with a larger number of respondents. Future studies should seek to increase the sample size and the power of the factor analyses.

\section{Conclusions}

This study found that dentists had both positive and negative attitudes towards communication skills learning. Considering the high NAS scores, communication skills formal training sessions should be introduced. Opportunities should be provided to learn communication skills through training enhanced by conducting continuing dental education and workshops. Further studies across the nation are required to gain an insight into the problems of communication skills training in Qatar.

\section{Acknowledgments}

We are grateful to all the dentist respondents for participating in the study.

\section{References}

[1]. Manogue M, Brown G, Foster H. Clinical assessment of dental students: values and practices of teachers in restorative dentistry. Med Educ. 2001 Apr;35(4):364-70. Pubmed PMID: 11319000.

[2]. Laurence B, Bertera EM, Feimster T, Hollander R, Stroman C. Adaptation of the Communication Skills Attitude Scale (CSAS) to dental students. J Dent Educ. 2012 Dec;76(12):1629-38. Pubmed PMID: 23225682.

[3]. White JG, Krüger C, Snyman WD. Development and implementation of communication skills in dentistry: an example from South Africa. Eur J Dent Educ. 2008 Feb;12(1):29-34. Pubmed PMID: 18257762.

[4]. Carey JA, Madill A, Manogue M. Communications skills in dental education: a systematic research review. Eur J Dent Educ. 2010 May;14(2):69-78. doi: Pubmed PMID: 20522105.

[5]. Hannah A, Millichamp CJ, Ayers KM. A communication skills course for undergraduate dental students. J Dent Educ. 2004 Sep;68(9):970-7.Pubmed PMID: 15342658

[6]. Nor NA, Yusof ZY, Shahidan MN. University of Malaya dental students' attitudes towards communication skills learning: implications for dental edu- 
cation. J Dent Educ. 2011 Dec;75(12):1611-9. Pubmed PMID: 22184601.

[7]. Yashoda, R.; Puranik, M. P., Dental students' attitude toward learning communication skills in Bengaluru city, India. J Indian Assoc Public Health Dent. 2016;14 (3): 327.

[8]. Cleland J, Foster K, Moffat M. Undergraduate students' attitudes to communication skills learning differ depending on year of study and gender. Med Teach. 2005 May;27(3):246-51. Pubmed PMID: 16011948.

[9]. Atteya, S., Saleh SM, Essam WA. Attitudes of dental interns towards learning communication skills in Alexandria University. Alex Dent J. 2017; 42,:20-27.

[10]. Woelber JP, Deimling D, Langenbach D, Ratka-Krüger P. The importance of teaching communication in dental education. A survey amongst dentists, students and patients. Eur J Dent Educ. 2012 Feb;16(1):e200-4. Pubmed PMID: 22251347.

[11]. Orsini CA, Jerez OM. Establishing a good dentist-patient relationship: skills defined from the dental faculty perspective. J Dent Educ. 2014 Oct;78(10):1405-15. Pubmed PMID: 25281674.

[12]. Kadanakuppe S. Effective Communication and Empathy Skills in Dentistry for Better Dentist-Patient Relationships. J Dent Probl Solut. 2015;2 (3): 058-059.

[13]. Hawken SJ. Good communication skills: benefits for doctors and patients. New Zealand Family Physician. 2005;32(3):185-9.

[14]. Lanning SK, Ranson SL, Willett RM. Communication skills instruction utilizing interdisciplinary peer teachers: program development and student perceptions. J Dent Educ. 2008 Feb;72(2):172-82. Pubmed PMID: 18250396.

[15]. Rees C, Sheard C. The relationship between medical students' attitudes towards communication skills learning and their demographic and educationrelated characteristics. Med Educ. 2002 Nov;36(11):1017-27. Pubmed PMID: 12406261.

[16]. Wiskin CM, Allan TF, Skelton JR. Gender as a variable in the assessment of final year degree-level communication skills. Med Educ. 2004 Feb;38(2):129-37. Pubmed PMID: 14871383.

[17]. Aspegren K. BEME Guide No. 2: Teaching and learning communication skills in medicine-a review with quality grading of articles. Med Teach. 1999;21(6):563-70. Pubmed PMID: 21281175. 